\title{
Anaerobic hydrocarbon and fatty acid metabolism by syntrophic bacteria and their impact on carbon steel corrosion
}

\author{
Christopher N. Lyles ${ }^{1}$, Huynh M. Le ${ }^{1}$, William Howard Beasley ${ }^{2}$, Michael J. Mclnerney ${ }^{1}$ and \\ Joseph M. Suflita ${ }^{1 *}$ \\ ${ }^{1}$ Department of Microbiology and Plant Biology, Institute for Energy and the Environment, and the OU Biocorrosion Center, University of Oklahoma, Norman, OK, \\ USA \\ 2 Howard Live Oak, LLC, Norman, OK, USA
}

\section{Edited by:}

Andreas Teske, University of North

Carolina at Chapel Hill, USA

Reviewed by:

Jason B. Sylvan, University of

Southern California, USA

Shawn R. Campagna, University of

Tennessee, Knoxville, USA

*Correspondence:

Joseph M. Suflita, Department of Microbiology and Plant Biology, OU

Biocorrosion Center, University of Oklahoma, 770 Van Vleet Oval,

Norman, OK 73019, USA

e-mail: jsuflita@ou.edu

The microbial metabolism of hydrocarbons is increasingly associated with the corrosion of carbon steel in sulfate-rich marine waters. However, how such transformations influence metal biocorrosion in the absence of an electron acceptor is not fully recognized. We grew a marine alkane-utilizing, sulfate-reducing bacterium, Desulfoglaeba alkanexedens, with either sulfate or Methanospirillum hungatei as electron acceptors, and tested the ability of the cultures to catalyze metal corrosion. Axenically, D. alkanexedens had a higher instantaneous corrosion rate and produced more pits in carbon steel coupons than when the same organism was grown in syntrophic co-culture with the methanogen. Since anaerobic hydrocarbon biodegradation pathways converge on fatty acid intermediates, the corrosive ability of a known fatty acid-oxidizing syntrophic bacterium, Syntrophus aciditrophicus was compared when grown in pure culture or in co-culture with a $\mathrm{H}_{2}$-utilizing sulfate-reducing bacterium (Desulfovibrio $s p$., strain $\mathrm{G} 11$ ) or a methanogen (M. hungatei). The instantaneous corrosion rates in the cultures were not substantially different, but the syntrophic, sulfate-reducing co-culture produced more pits in coupons than other combinations of microorganisms. Lactate-grown cultures of strain G11 had higher instantaneous corrosion rates and coupon pitting compared to the same organism cultured with hydrogen as an electron donor. Thus, if sulfate is available as an electron acceptor, the same microbial assemblages produce sulfide and low molecular weight organic acids that exacerbated biocorrosion. Despite these trends, a surprisingly high degree of variation was encountered with the corrosion assessments. Differences in biomass, initial substrate concentration, rates of microbial activity or the degree of end product formation did not account for the variations. We are forced to ascribe such differences to the metallurgical properties of the coupons.

Keywords: syntrophy, biocorrosion, microbiologically influenced corrosion (MIC), hydrocarbon degradation, fatty acid oxidation

\section{INTRODUCTION}

Anaerobic hydrocarbon biodegradation is metabolically coupled with the consumption of a variety of terminal electron acceptors (for recent reviews see, Callaghan, 2013; Heider and Schühle, 2013). It is essential to understand the underlying geochemical settings for such bioconversions in order to reliably assess the attendant environmental consequences. Arguably, the greatest impact of this metabolism is manifest in sulfate-laden environments where petroleum metabolism may be coupled with sulfide production. Aside from the destruction of the hydrocarbons per se, the formation of sulfide has several important consequences including health and safety concerns (Reiffenstein et al., 1992), reservoir souring (Jenneman et al., 1986; McInerney et al., 1996; Nemati et al., 2001; Hubert and Voordouw, 2007), and metal biocorrosion (Hamilton, 1985). Not surprisingly, these problems are most acute in marine environments where sulfatereducing bacterial communities thrive in petroleum deposits, hydrocarbon seeps, petroleum hydrothermal sediments, methane hydrates, oil field equipment, and in hydrocarbon-contaminated sediments (Teske, 2010). Moreover, in offshore and near coastal drilling operations where seawater is injected into petroleum reservoirs to maintain oil field formation pressures, efforts are regularly made to remove sulfate from seawater in order to control the deleterious consequences of scale deposits as well as to minimize microbial sulfate reduction, reservoir souring, and sulfide-induced metal corrosion (Bader, 2007). When exogenous electron acceptors are limiting, anaerobic hydrocarbon mineralization can still proceed and result in the formation of methane (Dolfing et al., 2008; Gieg et al., 2008; Jones et al., 2008; Heider and Schühle, 2013). In fact, methanogenic enrichments and isolates are regularly obtained from hydrocarbon-rich marine ecosystems (Teske, 2010), even though these organisms are not known to directly utilize petroleum components. Rather, acetoclastic and hydrogenotrophic methanogens catalyze the terminal 
mineralization steps as members of thermodynamically-based hydrocarbonoclastic syntrophic microbial assemblages of varying complexity (Dolfing et al., 2008; Gieg et al., 2008; Jones et al., 2008). The consequences of methanogenic hydrocarbon metabolism minimally include the overall diminution in the quality of petroleum reserves (Head et al., 2010), and the formation of methane a powerful greenhouse gas (Blake and Rowland, 1988). The other end product of this bioconversion, carbon dioxide, can potentially alter the in situ mineralization pathways in petroliferous reservoirs. If carbon dioxide is in a high enough concentration, acetoclastic methanogenesis may become a dominant process and increase the rate of methane production and sequestration of carbon dioxide (Mayumi et al., 2013).

Thus, the complete mineralization of hydrocarbons under anaerobic conditions, like the biodegradation of other complex forms of organic matter, can be initiated or accomplished by specialized microbial isolates that can couple this metabolism to the consumption of exogenous electron acceptors or enter into complex syntrophic partnerships. Such bioconversions often result in the transient formation of fatty acid metabolites (e.g., acetate, propionate, butyrate, and benzoate) that have been postulated as intermediates of anaerobic hydrocarbon metabolism under both methanogenic and sulfate-reducing conditions (Cozzarelli et al., 1994; Van Stempvoort et al., 2007, 2009; Struchtemeyer et al., 2011). In syntrophic partnerships, it is well known that non-methanogens, such as hydrogen/formate-utilizing, sulfatereducing bacteria (SRB), can fulfill the role of the terminal electron-accepting microorganism (Hopkins et al., 1995; Warikoo et al., 1996; Jackson et al., 1999). Conversely, a syntrophic association with methanogens can also be realized even in environments with high sulfate concentrations (Struchtemeyer et al., 2011).

The role of SRB and methanogens as agents of metal corrosion, when grown as pure cultures or as members of syntrophic consortia, is not fully appreciated. These organisms have been implicated in the corrosion of metal via direct electron transfer from zero-valent iron under electron donor-limited conditions (Dinh et al., 2004; Uchiyama et al., 2010; Enning et al., 2012; Enning and Garrelfs, 2014). Additionally, when electron donors are sufficient, the inorganic and organic compounds produced during metabolism (e.g., hydrogen, fatty acids, carbon dioxide, and sulfides) have frequently been associated with metal biocorrosion (King and Miller, 1971; King and Wakerley, 1972; King et al., 1973a,b; Crolet et al., 1999; Hedges and McVeigh, 1999; Garsany et al., 2003; Kermani and Morshed, 2003; Suflita et al., 2008).

Given the diverse modes of existence for the requisite microorganisms, we used defined incubations of both pure and co-culture syntrophic bacteria to examine their impact on carbon steel biocorrosion. More specifically, we evaluated a known hydrocarbon-degrading bacterium, Desulfoglaeba alkanexedens strain ALDC (Davidova et al., 2006), grown with sulfate or syntrophically in co-culture with a methanogen as the electron acceptor. D. alkanexedens strain ALDC is a marine alkane-degrading, sulfate-reducing bacterium, that can completely oxidize $\mathrm{C}_{6}-\mathrm{C}_{12} n$-alkanes via the fumarate addition pathway. The bacterium can also syntrophically degrade the same suite of aliphatic hydrocarbons in a sulfate-free medium when co-cultured with the hydrogen/formate-consuming methanogen, Methanospirillum hungatei strain JF-1 (Ferry et al., 1974). We also evaluated biocorrosion with a known fatty acid-oxidizing syntrophic bacterium, Syntrophus aciditrophicus strain SB (Hopkins et al., 1995; Jackson et al., 1999), grown as a pure culture or with either a hydrogen/formate-utilizing methanogen or SRB as the electron-accepting microorganism. S. aciditrophicus strain SB, metabolizes various saturated and unsaturated fatty acids, methyl esters of butyrate and hexanoate, benzoate, and alicyclic acids when grown in co-culture with a hydrogen/formate-consuming microorganism (Mouttaki et al., 2007) including the methanogen M. hungatei strain JF-1 or the SRB Desulfovibrio sp. strain G11 (McInerney et al., 1979). Its use of a primary sodium pump to create a chemostatic potential and to synthesize ATP using a sodium gradient mimics the bioenergetic scheme of many marine microorganisms (McInerney et al., 2007). Similarly, M. hungatei strain JF-1 also has the capacity to produce and use sodium gradients (Anderson et al., 2009). S. aciditrophicus strain SB can also be grown as a pure culture on crotonate whereupon it produces acetate, cyclohexane carboxylate, and benzoate as metabolic end products (Mouttaki et al., 2007). Lastly, all pure cultures were individually evaluated for their ability to corrode metal coupons. Our results suggest that the corrosion of carbon steel was generally more evident when anaerobic microbial metabolism was linked to sulfate reduction rather than methanogenesis. However, a greater than expected standard deviation in corrosivity was measured in replicate incubations. After controlling and monitoring the biological and chemical characteristics of the incubations, we are forced to attribute the variability to presumed compositional differences in the metal used for the construction of the coupons.

\section{MATERIALS AND METHODS ELECTROCHEMICAL CELL CONSTRUCTION}

Electrochemical cells were made from culture bottles $(100 \mathrm{ml}$; Figure S1) fitted with rubber stoppers that were modified to hold a graphite counter electrode and a Luggin probe filled with $1 \mathrm{M}$ potassium chloride $(\mathrm{KCl})$ solution containing a saturated calomel reference electrode (Gamry Instruments, Warminster, PA; Figure S2). The working electrode was a 1020 carbon steel coupon (Alabama Specialty Products, Munford, AL) with dimensions of $0.95 \mathrm{~cm}$ diameter $\times 1.27 \mathrm{~cm}$ and a surface area of $4.5 \mathrm{~cm}^{2}$. The metal was prepared using the specifications detailed in ASTM Standard A576-90b (2006), and consisted of the elemental components listed in Table S1 according to the manufacturer (above). A wire was attached to the coupon using rosin core solder and the entire assembly was sealed with epoxy resin (Figure S3). The working electrode assembly was then washed with acetone and methanol, before being sterilized by immersion for $30 \mathrm{~min}$ in a $70 \%$ ethanol bath. The ethanol was evaporated with an open flame, and the coupon was dried under nitrogen and handled aseptically. Sterile electrochemical probes (Figure S2) were placed in the incubations (Figure S4) while inside a well-working anaerobic chamber $\left(\mathrm{N}_{2}: \mathrm{H}_{2} 95: 5 \%\right)$, and linear polarization resistance (LPR) curves were recorded every $5 \mathrm{~min}$ for a $30 \mathrm{~min}$ period using computer controlled potentiostats (model 600, Gamry Instruments, Warminster, PA). The potential was swept $\pm 10 \mathrm{mV}$ 
above and below the corrosion potential $\left(E_{\text {corr }}\right)$ at a rate of $0.125 \mathrm{mV} / \mathrm{s}$. Tafel slope regions were used to extrapolate resistance polarization $\left(R_{p}\right)$ values within $\pm 5 \mathrm{mV}$ of the $E_{c o r r}$. The instantaneous corrosion rate is derived by taking the inverse of the resistance polarization $\left(1 / R_{p} ; \mathrm{ohms}^{-1} \mathrm{~cm}^{-2}\right)$. The LPR measurement was taken intermittently based on the metabolic activity measured within anaerobic incubations (below). Thus, the $1 / R_{p}$ curves reflect various points along the curve shown in Figure 1. A $1 / R_{p}$ value for each time point was selected based on the mean distribution of six LPR curves within the 30 min measurement period. Finally, instantaneous corrosion rates were generalized as low $[<0.0254$ millimeter per year $(\mathrm{mmpy})]$, moderate $(0.0254-$ $0.127 \mathrm{mmpy})$, or high $(0.127-0.508 \mathrm{mmpy})$ based on the $1 / R_{p}$ logarithmic value (Figure 1).

\section{CULTIVATION OF THE HYDROCARBON-DEGRADING BACTERIUM}

The mineral medium was prepared as previously described (McInerney et al., 1979), except rumen fluid and sulfate were omitted. The medium was amended with $10 \mathrm{ml} / \mathrm{L}$ of a trace metal and vitamin solution (Tanner, 2002), 0.0001\% solution of resazurin as a redox indicator, sodium bicarbonate $(24 \mathrm{mM})$, and $10 \mathrm{ml} / \mathrm{L}$ of a $2.5 \%$ solution of cysteine sulfide used as a reductant. The medium was dispensed into the electrochemical cells $(50 \mathrm{ml})$ and inoculated with $20 \%$ transfers for the $D$. alkanexedens strain ALDC or M. hungatei strain JF-1 pure culture incubations or $10 \%$ transfers of each microorganism for the co-culture incubations. The mineral medium was the same for all axenic cultures or co-cultures, but the substrate, sulfate concentration, and headspace gas composition were adjusted for different incubation conditions (Table 1). The headspace for the axenic cultures of $M$. hungatei strain JF-1 was monitored and exchanged every 14 days to resupply $\mathrm{H}_{2} / \mathrm{CO}_{2}$ to support the hydrogenotrophic growth of the methanogen. Strict anaerobic conditions were maintained throughout the 44 days incubation period. Triplicate cultures were incubated at $32^{\circ} \mathrm{C}$ and monitored

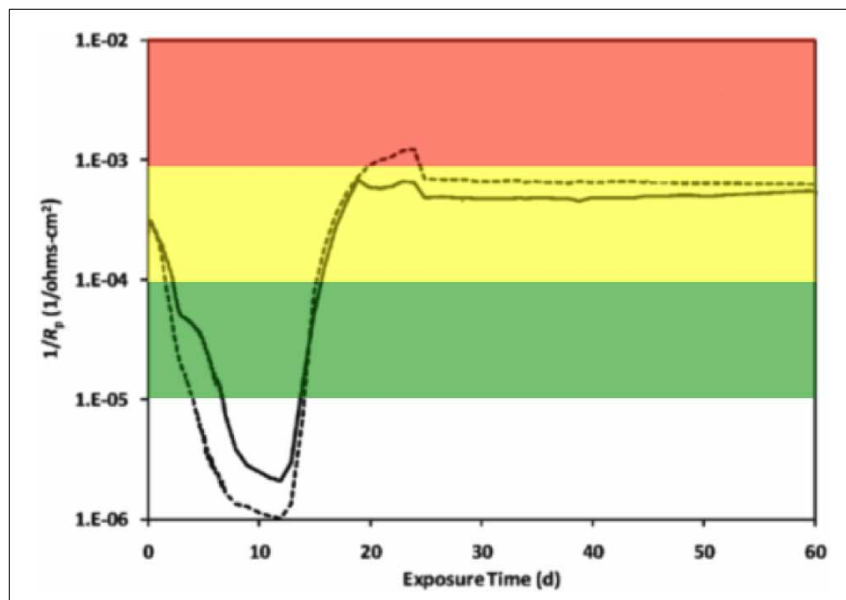

FIGURE 1 | An instantaneous corrosion rate $\left(1 / R_{p}\right)$ curve adapted from Aktas et al. (2010). The basic shape of the curve represents the corrosion of C1020 metal over time. $1 / R_{p}=$ (口) $10^{-5} \mathrm{ohms}^{-1} \mathrm{~cm}^{-2},<0.0254 \mathrm{mmpy}$; ( ) $10^{-4} \mathrm{ohms}^{-1} \mathrm{~cm}^{-2}, 0.0254-0.127 \mathrm{mmpy}$; ( $10^{-3} \mathrm{ohms}^{-1} \mathrm{~cm}^{-2}$ ， 0.127-0.508 mmpy. for corrosion with the potentiostats every 26 days after moving the cultures inside the anaerobic chamber. After each LPR measurement, the culture bottles were resealed and the headspace exchanged to the appropriate atmosphere.

\section{CULTIVATION OF THE FATTY ACID-OXIDIZING SYNTROPH}

A basal medium was prepared as previously described (Tanner, 2002), and was amended with $10 \mathrm{ml} / \mathrm{L}$ trace metal and vitamin solution (Tanner, 2002), a $0.0001 \%$ solution of resazurin as a redox indicator, sodium bicarbonate $(24 \mathrm{mM})$, and $20 \mathrm{ml} / \mathrm{L}$ of a $2.5 \%$ solution of cysteine sulfide used as a reductant. The medium was dispensed into the electrochemical cells $(50 \mathrm{ml})$ and inoculated with $20 \%$ transfers of S. aciditrophicus strain SB or Desulfovibrio sp. strain G11 pure cultures, or 10\% transfers of each of the microorganisms for the syntrophic co-culture incubations. The basal medium was the same for all cultures and cocultures, but the substrate, sulfate concentration, and headspace atmosphere were adjusted depending on the desired incubation condition (Table 2). The headspace in autotrophically grown Desulfovibrio sp. strain G11 incubations was exchanged daily to resupply $\mathrm{H}_{2} / \mathrm{CO}_{2}$ to support the growth of this microorganism. Cultures were incubated in triplicate while medium controls were in duplicate. Incubations were held at $32^{\circ} \mathrm{C}$ and monitored electrochemically for the instantaneous corrosion rate as described above, every 7 days (experiment 1 ) or 28 days (experiment 2) after placing the cultures inside the anaerobic chamber. After each LPR measurement, the culture bottles were resealed and the headspace exchanged to the original atmosphere.

\section{SPENT MEDIUM EXPERIMENTS}

The corrositivity of the basal medium (Tanner, 2002) was assessed after amendment with various fatty acids with concentrations of crotonate and lactate ranging from 0 to $20 \mathrm{mM}$, as well as acetate ranging from 0 to $40 \mathrm{mM}$. These compounds were exogenously amended to mimic the concentration of substrates and end products produced by a crotonate grown co-culture of $S$. aciditrophicus strain SB and Desulfovibrio sp. strain G11 and lactate metabolism by a pure culture of Desulfovibrio sp. strain G11. Acetate was amended at a ratio of 2:1 for crotonate metabolism and 1:1 for

Table 1 | Substrate, sulfate, and headspace amendments for hydrocarbon degrading incubations.

\begin{tabular}{llcl}
\hline $\begin{array}{l}\text { Axenic or } \\
\text { co-culture } \\
\text { incubations }\end{array}$ & Substrate & $\begin{array}{c}\text { Sulfate } \\
\text { (mM) }\end{array}$ & $\begin{array}{l}\text { Headspace } \\
\text { atmosphere }\end{array}$ \\
\hline $\begin{array}{l}\text { D. alkanexedens } \\
\text { ALDC }\end{array}$ & $1 \mathrm{ml} n$-decane & 20 & $138 \mathrm{kPa} \mathrm{N} / \mathrm{CO}_{2}$ \\
$\begin{array}{l}\text { M. hungatei JF-1 } \\
\mathrm{H}_{2} / \mathrm{CO}_{2}(138 \mathrm{kPa} \text { in }\end{array}$ & - & $138 \mathrm{kPa}$ \\
$\begin{array}{l}\text { D. alkanexedens } \\
\text { ALDC }+M \text {. }\end{array}$ & $1 \mathrm{ml}$-decane & - & $\begin{array}{l}\mathrm{H}_{2} / \mathrm{CO}_{2}(5: 95) \\
138 \mathrm{kPa}\end{array}$ \\
$\begin{array}{l}\text { hungatei JF-1 } \\
\begin{array}{l}\text { Uninoculated } \\
\text { medium control }\end{array}\end{array}$ & $1 \mathrm{ml} n$-decane & & $\mathrm{N}_{2} / \mathrm{CO}_{2}(80: 20)$ \\
\hline
\end{tabular}

"-, No amendment. 
Table 2 | Substrate, sulfate, and headspace amendments for fatty acid oxidizing incubations.

\begin{tabular}{|c|c|c|c|}
\hline $\begin{array}{l}\text { Axenic or } \\
\text { co-culture } \\
\text { incubations }\end{array}$ & Substrate & $\begin{array}{c}\text { Sulfate } \\
\text { (mM) }\end{array}$ & $\begin{array}{l}\text { Headspace } \\
\text { atmosphere }\end{array}$ \\
\hline S. aciditrophicus SB & $\begin{array}{l}20 \mathrm{mM} \\
\text { crotonate }\end{array}$ & - & $\begin{array}{l}138 \mathrm{kPa} \mathrm{N} / \mathrm{CO}_{2} \\
(80: 20)\end{array}$ \\
\hline $\begin{array}{l}\text { S. aciditrophicus SB + } \\
\text { Desulfovibrio sp. G11 }\end{array}$ & $\begin{array}{l}20 \mathrm{mM} \\
\text { crotonate }\end{array}$ & 20 & $\begin{array}{l}138 \mathrm{kPa} \mathrm{N} / \mathrm{CO}_{2} \\
(80: 20)\end{array}$ \\
\hline $\begin{array}{l}\text { S. aciditrophicus SB + } \\
\text { M. hungatei JF-1 }\end{array}$ & $\begin{array}{l}20 \mathrm{mM} \\
\text { crotonate }\end{array}$ & - & $\begin{array}{l}138 \mathrm{kPa} \mathrm{N} / \mathrm{CO}_{2} \\
(80: 20)\end{array}$ \\
\hline $\begin{array}{l}\text { Desulfovibrio sp. G11 } \\
\text { (heterotrophic) }\end{array}$ & $\begin{array}{l}20 \mathrm{mM} \\
\text { lactate }\end{array}$ & 20 & $\begin{array}{l}138 \mathrm{kPa} \mathrm{N} / \mathrm{CO}_{2} \\
(80: 20)\end{array}$ \\
\hline $\begin{array}{l}\text { Desulfovibrio sp. G11 } \\
\text { (autotrophic) }\end{array}$ & $\begin{array}{l}\mathrm{H}_{2} / \mathrm{CO}_{2}(138 \mathrm{kPa} \\
\text { in } \sim 40 \mathrm{mls} \text { of } \\
\text { headspace })\end{array}$ & 20 & $\begin{array}{l}138 \mathrm{kPa} \\
\mathrm{H}_{2} / \mathrm{CO}_{2}(5: 95)\end{array}$ \\
\hline $\begin{array}{l}\text { Desulfovibrio sp. G11 } \\
\text { (autotrophic) }\end{array}$ & $\begin{array}{l}\mathrm{H}_{2} \text { from metal } \\
\text { surface }\end{array}$ & 20 & $\begin{array}{l}138 \mathrm{kPa} \mathrm{N} / \mathrm{CO}_{2} \\
(80: 20)\end{array}$ \\
\hline $\begin{array}{l}\text { Uninoculated medium } \\
\text { control }\end{array}$ & $\begin{array}{l}20 \mathrm{mM} \\
\text { crotonate }\end{array}$ & - & $\begin{array}{l}138 \mathrm{kPa} \mathrm{N} / \mathrm{CO}_{2} \\
(80: 20)\end{array}$ \\
\hline $\begin{array}{l}\text { Uninoculated medium } \\
\text { control }\end{array}$ & $\begin{array}{l}20 \mathrm{mM} \\
\text { lactate }\end{array}$ & 20 & $\begin{array}{l}138 \mathrm{kPa} \mathrm{N} / \mathrm{CO}_{2} \\
(80: 20)\end{array}$ \\
\hline $\begin{array}{l}\text { Uninoculated medium } \\
\text { control }\end{array}$ & - & 20 & $\begin{array}{l}138 \mathrm{kPa} \\
\mathrm{H}_{2} / \mathrm{CO}_{2} \mathrm{Or} \\
138 \mathrm{kPa} \mathrm{N} / \mathrm{CO}_{2}\end{array}$ \\
\hline
\end{tabular}

"-," No amendment.

lactate metabolism. To represent sulfide production within the uninocultated incubations, sodium sulfide was amended at 10 and $20 \mathrm{mM}$ concentrations. The $\mathrm{pH}$ for all incubations was $\sim 7.0$. The incubation conditions are described in Table 3. Duplicate uninoculated incubations were held at $32^{\circ} \mathrm{C}$ and monitored electrochemically every 17 days inside the anaerobic chamber as described above.

\section{PROFILOMETRY}

At the end of the incubation, the coupons were recovered and localized corrosion damage was assessed with light profilometry (PS50 profilometer, Nanovea, Irvine, CA). The coupons were acid-cleaned to remove corrosion deposits according to ASTM Standard A576-90b (2006). The initial surface profiling of coupons was conducted by a cooperating external laboratory (Phillips 66, Bartlesville, OK, USA). However, a model PS50 profilometer (Nanovea, Irvine, CA) was eventually acquired for this purpose. Only the flat surface of the cylindrical coupons were analyzed for localized pitting evaluations. Line scans were run at a data acquisition rate of $2000 \mathrm{~Hz}$ using a $300 \mu \mathrm{m}$ optical pen at a $3.0 \mu \mathrm{m}$ step size. All surface analysis was performed using 3D analysis software (Ultra v6.2 Nanovea, Irvine, CA). Pitting was defined as damage that was $20 \mu \mathrm{m}$ below the mean surface plane and at least a $20 \mu \mathrm{m}$ in diameter. These experimental parameters were chosen based on the distribution of collected points across all coupons analyzed. Surface damage was also assessed by comparing histograms for each coupon.
Table 3 | Uninoculated medium controls containing various concentrations of fatty acids and sulfide amended to represent crotonate metabolism by $\boldsymbol{S}$. aciditrophicus strain SB or lactate metabolism by Desulfovibrio sp. strain G11.

\begin{tabular}{ll}
\hline Crotonate metabolism & Lactate metabolism \\
\hline $20 \mathrm{mM}$ crotonate & $20 \mathrm{mM}$ lactate \\
$10 \mathrm{mM}$ crotonate $+20 \mathrm{mM}$ & $10 \mathrm{mM}$ lactate $+10 \mathrm{mM}$ acetate \\
acetate $+10 \mathrm{mM}$ sulfide & $+10 \mathrm{mM}$ sulfide \\
$0 \mathrm{mM}$ crotonate $+40 \mathrm{mM}$ acetate & $0 \mathrm{mM}$ lactate $+20 \mathrm{mM}$ acetate + \\
$+20 \mathrm{mM}$ sulfide & $20 \mathrm{mM}$ sulfide \\
No amendment medium control & No amendment medium control \\
\hline
\end{tabular}

Each histogram consists of 2501 points collected from the profilometer. The $y$ value indicates the depth $(\mu \mathrm{m})$ of the points while the $x$ value is the percentage of points at that particular depth.

\section{STATISTICAL METHODS}

All statistical analyses were done using $\mathrm{R}$ (The R Foundation for statistical computing). Treatment means were estimated by a Bayesian multilevel model that accounted for the dependencies among the 2501 points from each coupon. Using the MCMCglmm package (Hadfield, 2010) and vauge priors, eight parallel MCMC chains were run for 10,000 iterations after burnin; the largest $\boldsymbol{R}$ was less than 1.001. Our primary model produced point and error estimates consistent with a frequentist multilevel model (using the lme4 package; Bates, 2010) and with a frequentist ANOVA (that considered only the mean of each coupon). Coupons not scanned at the University of Oklahoma were excluded from the analysis since a different profilometry protocol was employed and the resulting histograms were not comparable. In addition, a medium control coupon was similarly excluded since it had a damaged area on its surface (but no pits matching the experimental parameters were evident). To be entirely transparent, a comparison of the datasets with and without the outliers is depicted in the supplemental information (see Figure S21). To facilitate reproducibility, the code and profilometry data are available at https://github.com/LiveOak/ LylesCarbonSteelCorrosion.

\section{ANALYTICAL METHODS}

Crotonate loss was measured by HPLC (Dionex model IC-3000, Sunnyvale, CA) using an Alltech Prevail ${ }^{\mathrm{TM}}$ organic acid column $(250 \times 4.6 \mathrm{~mm}$, particle size $5 \mu \mathrm{M}$; Grace, Deerfield, IL) and UV absorbance dector (Dionex model AD25, Sunnyvale, CA). The gradient pump was operated at a flow rate of $1.0 \mathrm{ml} / \mathrm{min}$ and mixed a mobile phase consisting of $60 \%$ (vol/vol) $\mathrm{KH}_{2} \mathrm{PO}_{4}$ (25 mM, pH 2.5) and 40\% acetonitrile. The UV absorbance detector was set to $254 \mathrm{~nm}$. Sulfate depletion was analyzed by ion chromatography (Dionex model IC-1000, Sunnyvale, CA) and has been previously described in Lyles et al. (2013). Methane production was monitored by gas chromatography (Packard model 427, Downers Grove, Ill.) and has been previously described in Gieg et al. (2008). 


\section{RESULTS}

ANAEROBIC HYDROCARBON BIODEGRADATION AND THE CORROSION OF CARBON STEEL

There are many important ecological consequences associated with anaerobic hydrocarbon biodegradation in the environment. We used pure cultures and defined co-cultures to investigate the impact of this metabolism on one of the most important ecological consequences, the biocorrosion of carbon steel. D. alkanexedens strain ALDC and M. hungatei strain JF-1 were cultured axenically and as a syntrophic partner in the presence of carbon steel coupons. Coupon damage was assessed by periodically measuring the instantaneous corrosion rate during the course of the experiment and by surface profilometry at the end of the incubation period (Table 4).

After 44 days of incubation, D. alkanexedens strain ALDC cultured on $n$-decane reduced sulfate at a rate of $0.060 \pm$ $0.014 \mathrm{mM} \mathrm{SO}_{4} \bullet$ day $^{-1}$ (Figure S5) and produced an instantaneous corrosion rate of $7.8 \times 10^{-3} \pm 8.3 \times 10^{-4} \mathrm{ohms}^{-1}$ $\mathrm{cm}^{-2}(\sim 0.381 \mathrm{mmpy}$; Figure 2$)$. Approximately $18 \%$ of the $n$-decane was oxidized during the incubation period based on the amount of sulfate reduced within the incubation (data not shown). When D. alkanexedens strain ALDC and M. hungatei strain JF-1 were co-cultured on the same hydrocarbon, an average of $62.0 \pm 22.5 \mu$ mole methane (Figure S6) was produced, suggesting that $\sim 0.2 \%$ of the parent hydrocarbon was utilized by the co-culture. The instantaneous corrosion rate for the co-culture was $7.0 \times 10^{-4} \pm 4.3 \times 10^{-4} \mathrm{ohms}^{-1} \mathrm{~cm}^{-2}$ ( $\sim 0.0508$ mmpy; Figure 2). Pure cultures of $M$. hungatei strain JF-1 cultured hydrogenotrophically $\left(\mathrm{H}_{2} / \mathrm{CO}_{2}\right)$ produced $\sim 1500$ $\pm 700 \mu$ mole methane over the initial 24 days incubation but the rate decreased with each headspace exchange over the entire incubation (Figure S7). The pure methanogen exhibited an instantaneous corrosion rate of $6.56 \times 10^{-5} \pm 4.4 \times 10^{-5} \mathrm{ohms}^{-1} \mathrm{~cm}^{-2}$ $(<0.0254 \mathrm{mmpy})$; a value that was even lower than the comparable rate determination in the uninoculated control $\left(1.01 \times 10^{-4}\right.$ $\left.\pm 4.48 \times 10^{-5} \mathrm{ohms}^{-1} \mathrm{~cm}^{-2} ;<0.0254 \mathrm{mmpy}\right)$.

When profilometry was used to assess localized corrosion in the coupons, differences between replicate incubations were evident (Table 4; Figure S8). One coupon replicate in the $D$.

Table 4 | The number of pits and the instantaneous corrosion rates for replicates of the hydrocarbon and fatty acid oxidizing cultures as well as the spent medium incubations.

Incubation condition (substrate amendment) Number of pits + instantaneous corrosion rate $\left(1 / R_{p}\right)$

\begin{tabular}{|c|c|c|c|c|c|}
\hline \multicolumn{3}{|c|}{ Experiment 1} & \multicolumn{3}{|c|}{ Experiment 2} \\
\hline Replicate 1 & Replicate 2 & Replicate 3 & Replicate 1 & Replicate 2 & Replicate 3 \\
\hline
\end{tabular}

\section{HYDROCARBON DEGRADING CULTURES}

D. alkanexedens ALDC (n-decane)

D. alkanexedens ALDC $+M$. hungatei JF-1 (n-decane)

M. hungatei JF-1 $\left(\mathrm{H}_{2} / \mathrm{CO}_{2}\right)$

Uninoculated basal medium (n-decane)

\section{FATTY ACID OXIDIZING CULTURES}

\section{$S$. aciditrophicus SB (crotonate)}

S. aciditrophicus SB $+M$. hungatei JF-1 (crotonate)

S. aciditrophicus SB + Desulfovibrio sp. G11 (crotonate)

Desulfovibrio sp. G11 (lactate)

Desulfovibrio sp. $\mathrm{G} 11\left(\mathrm{H}_{2} / \mathrm{CO}_{2}\right)$

Desulfovibrio sp. $\mathrm{G} 11\left(\mathrm{H}_{2}\right.$ from metal surface)

Uninoculated basal medium (crotonate)

Uninoculated basal medium (lactate)

Uninoculated basal medium $\left(\mathrm{H}_{2} / \mathrm{CO}_{2}\right)$

\section{SPENT MEDIUM INCUBATIONS}

\section{$20 \mathrm{mM}$ crotonate}

$10 \mathrm{mM}$ crotonate $+20 \mathrm{mM}$ acetate $+10 \mathrm{mM}$ sulfide

$0 \mathrm{mM}$ crotonate $+40 \mathrm{mM}$ acetate $+20 \mathrm{mM}$ sulfide

$20 \mathrm{mM}$ lactate

$10 \mathrm{mM}$ lactate $+10 \mathrm{mM}$ acetate $+10 \mathrm{mM}$ sulfide

$0 \mathrm{mM}$ lactate $+20 \mathrm{mM}$ acetate $+20 \mathrm{mM}$ sulfide

Unamended basal medium control

ND, Not detectable.

"-," Replicate not done or data not available.

*The metal had pitting on the side but could not be quantified by the profilometer.

$1 / R_{p}=10^{-5}$ ohms $^{-1} \mathrm{~cm}^{-2},<0.0254 \mathrm{mmpy} ; 10^{-4} \mathrm{ohms}^{-1} \mathrm{~cm}^{-2}, 0.0254-0.127 \mathrm{mmpy}$; 


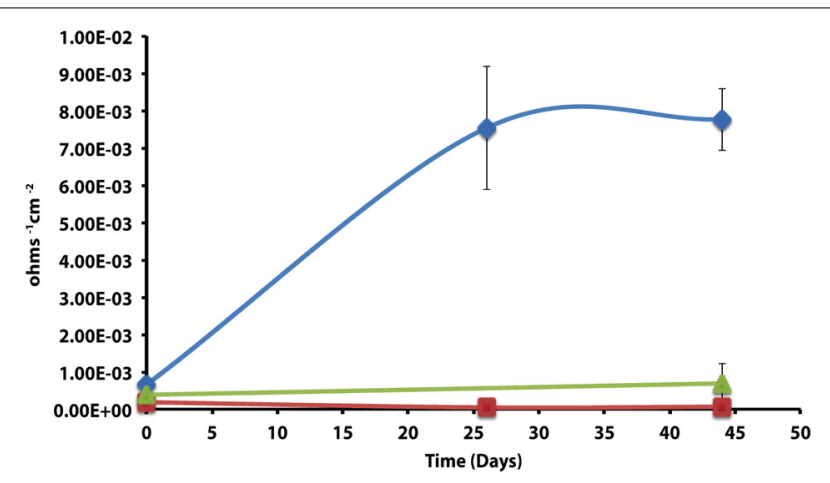

FIGURE 2 | Instantaneous corrosion rates $(1 / R p)$ for pure cultures of $D$. alkanexedens strain ALDC $(O)$ and $M$. hungatei strain JF-1 $(\square)$ as well as the syntrophic co-culture $(\triangle)$ of the two microorganisms (standard deviation incubations $n=3$, axenic $D$. alkanexedens strain ALDC incubations $n=2$ ). alkanexedens strain ALDC incubation exhibited substantial pitting (259 pits) while pits were not evident on the other replicate coupon despite similar sulfate reduction (Figure S5) and instantaneous corrosion rates (Figure 2). Pitting was not as severe for coupon replicates incubated in the syntrophic co-culture. That is, 66 pits were counted on replicate one, 3 pits on replicate two, and 0 pits on replicate three. The pure culture incubation of M. hungatei strain JF-1 and the uninoculated control had 2 and 50 pits, respectively.

\section{ANAEROBIC FATTY ACID BIODEGRADATION AND THE CORROSION OF CARBON STEEL}

The corrosion potential of the fatty acid-oxidizing syntroph, S. aciditrophicus strain SB, was evaluated in a similar manner by growing the bacterium, as a pure culture or in defined co-culture with $M$. hungatei strain JF-1 or Desulfovibrio sp. strain G11 (Table 4; Figure 3). The instantaneous corrosion rates were not substantially different between the pure culture of S. aciditrophicus strain SB and co-cultures M. hungatei strain JF-1 or Desulfovibrio sp. strain G11. However, localized corrosion increased when $S$. aciditrophicus strain SB was co-cultured with Desulfovibrio sp. strain G11 compared to when the syntroph was grown as a pure culture or when it was coupled with the methanogen (Table 4). Additionally, localized corrosion was also evident when coupons were exposed to pure cultures of Desulfovibrio sp. strain G11 grown in lactate-amended incubations with sulfate as the electron acceptor.

The instantaneous corrosion rates for pure cultures of $S$. aciditrophicus strain SB and related co-cultures are compared in Figure 3. Incubations containing axenic cultures of S. aciditrophicus strain SB were found to produce an instantaneous corrosion rate of $1.12 \times 10^{-3} \pm 9.65 \times 10^{-4} \mathrm{ohms}^{-1} \mathrm{~cm}^{-2}$ $(\sim 0.0762 \mathrm{mmpy})$. In co-culture with $M$. hungatei strain JF$1,15.65 \pm 7.16 \mu$ mole methane was produced over the 16 days incubation period (Figure S9), and the instantaneous corrosion rate was $2.64 \times 10^{-3} \pm 2.91 \times 10^{-3} \mathrm{ohms}^{-1}$ $\mathrm{cm}^{-2}$ ( $\sim 0.178 \mathrm{mmpy}$ ). When co-cultured with Desulfovibrio sp.

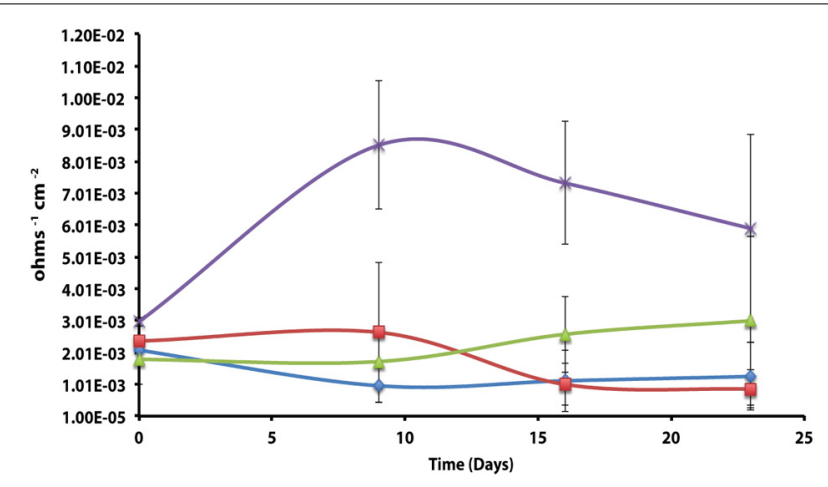

FIGURE 3 | Instantaneous corrosion rates (1/Rp) for pure cultures of $S$. aciditrophicus strain SB $(O)$ and syntrophic co-cultures with $M$. hungatei strain JF-1 $(\square)$ and Desulfovibrio sp. strain G11 ( $\triangle$ ) as well as an uninoculated basal medium controls amended with $20 \mathrm{mM}$ of crotonate $(X)$ (standard deviation incubations $n=3$, medium controls $n=2)$.

strain $\mathrm{G} 11$, the sulfate reduction rate was $0.34 \pm 0.08 \mathrm{mM}$ $\mathrm{SO}_{4} \bullet$ day $^{-1}$ (Figure S10), and the instantaneous corrosion rate was $2.6 \times 10^{-3} \pm 1.19 \times 10^{-3} \mathrm{ohms}^{-1} \mathrm{~cm}^{-2}(\sim 0.1524 \mathrm{mmpy})$. Uninoculated basal medium controls amended with $20 \mathrm{mM}$ of crotonate had an instantaneous corrosion rate of $7.33 \times$ $10^{-3} \pm 2.01 \times 10^{-3} \mathrm{ohms}^{-1} \mathrm{~cm}^{-2}(\sim 0.4318 \mathrm{mmpy})$. In all incubations containing $S$. aciditrophicus strain SB, crotonate was not detected by HPLC after 14 days of incubation (Figure S11). Additionally, the large standard deviations observed between $1 / R_{p}$ values (Figure 3 ) associated with incubations of $S$. aciditrophicus strain $\mathrm{SB}$ and related co-cultures suggest that there is no difference in instantaneous corrosion rates, despite the formation of different metabolic end products (i.e., sulfide, methane, acetate) within each of the various incubation conditions.

Axenic incubations of Desulfovibrio sp. strain G11 cultured in the same media but amended with $20 \mathrm{mM}$ of lactate produced an instantaneous corrosion rate of $1.5 \times 10^{-3} \pm$ $6.0 \times 10^{-4} \mathrm{ohms}^{-1} \mathrm{~cm}^{-2}(\sim 0.089 \mathrm{mmpy}$; Figure 4). These incubations reduced sulfate at a rate of $2.00 \pm 0.1 \mathrm{mM} \mathrm{SO}_{4} \bullet$ day $^{-1}$ (Figure S10). The uninoculated media control containing $20 \mathrm{mM}$ of lactate produced an instantaneous corrosion rate of $3.2 \times$ $10^{-3} \pm 6.0 \times 10^{-4} \mathrm{ohms}^{-1} \mathrm{~cm}^{-2}(\sim 0.1778 \mathrm{mmpy}$; Figure 4). Thus, there is no significant difference for the instantaneous corrosion rates between Desulfovibrio sp. strain G11 and uninoculated control incubations. Additionally, when Desulfovibrio sp. strain G11 was cultured autotrophically with $138 \mathrm{kPa}$ overpressure of $\mathrm{H}_{2} / \mathrm{CO}_{2}$ in the headspace as well as from hydrogen emanating from the metal surface, the sulfate reduction rate was $0.79 \pm 0.04 \mathrm{mM} \mathrm{SO}_{4} \bullet$ day $^{-1}$ and $0.35 \pm 0.10 \mathrm{mM} \mathrm{SO}_{4} \bullet$ day $^{-1}$, respectively (Figure S10). In all replicates of autotrophicallygrown cultures of this microorganism, the instantaneous corrosion rates (Figure 5) ranged between $5.17 \times 10^{-5} \pm 4.70 \times 10^{-5}$ and $5.51 \times 10^{-5} \pm 3.51 \times 10^{-5} \mathrm{ohms}^{-1} \mathrm{~cm}^{-2}(<0.0208 \mathrm{mmpy})$, which is lower than the uninoculated controls containing either $138 \mathrm{kPa}$ of $\mathrm{H}_{2} / \mathrm{CO}_{2}$ or $\mathrm{N}_{2} / \mathrm{CO}_{2}$ in the headspace $\left(1.02 \times 10^{-4} \pm\right.$ $\left.1.13 \times 10^{-4} \mathrm{ohms}^{-1} \mathrm{~cm}^{-2}\right)$. 


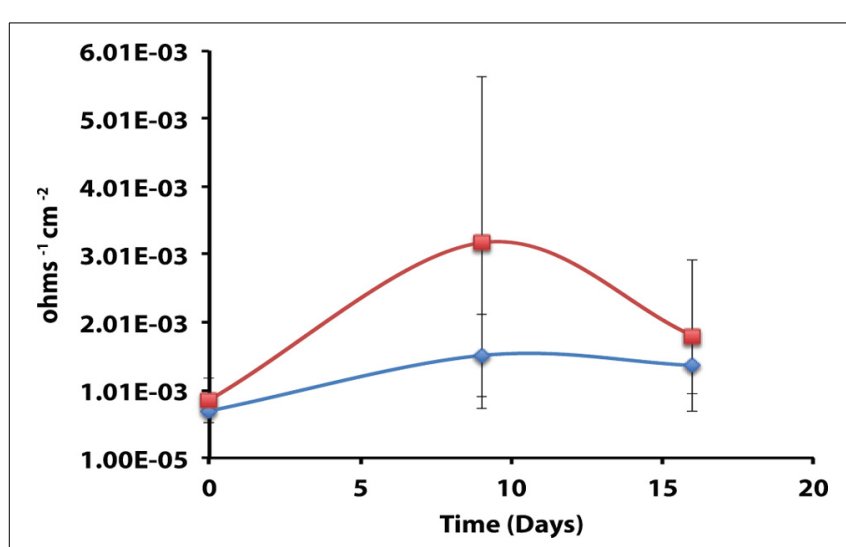

FIGURE 4 | Instantaneous corrosion rates (1/Rp) for lactate-amended pure cultures of Desulfovibrio sp. strain G11 $(\diamond)$ and uninoculated basal medium controls amended with $20 \mathrm{mM}$ lactate $(\square)$ (standard deviation incubations $n=3$, medium controls $n=2$ ).

Carbon steel coupons were assessed for localized corrosion using profilometry, and the numbers of pits counted from surface profiles (Figure S12) are compared in Table 4 (experiment 1). Even though pure cultures of S. aciditrophicus strain SB produced instantaneous corrosion rates of $10^{-3}$ and $10^{-4}$, only 2 pits were identified on the metal surface. When $S$. aciditrophicus strain SB was co-cultured with Desulfovibrio sp. strain G11, an average of $35 \pm 2.6$ pits were identified across the three replicates. Finally, when $S$. aciditrophicus strain SB was cocultured with $M$. hungatei strain JF-1, one replicate produced 88 pits, while the other replicates had no detectable pits. When coupons were exposed to pure cultures of Desulfovibrio sp. strain G11 grown on lactate, replicate one had no pits, but replicates two and three had 23 and 12 pits, respectively. No pits were detected on coupons analyzed from incubations containing Desulfovibrio sp. strain G11 cultured under autotrophic conditions. Additionally, exposure to uninoculated medium amended with $20 \mathrm{mM}$ crotonate caused one out of two metal samples to produce 45 pits.

Given the unexpectedly high level of variability encountered, the same experiments were repeated with the same degree of replication. With few exceptions, the instantaneous corrosion rates were largely in the $10^{-5} \mathrm{ohms}^{-1} \mathrm{~cm}^{-2}$ range (Table 4 experiment 2; Figure S13), and pitting was mainly associated with the S. aciditrophicus strain SB and Desulfovibrio sp. strain G11 co-cultures (Table 4 experiment 2; Figure S14). S. aciditrophicus strain SB alone or in co-culture with Desulfovibrio sp. strain G11 metabolized $\sim 2 \mathrm{mM}$ crotonate over the 30 days incubation (Figure S15), and the co-culture incubation reduced sulfate at $0.30 \pm 0.08 \mathrm{mM}$ $\mathrm{SO}_{4} \bullet \mathrm{day}^{-1}$ (Figure S16). For comparison, Desulfovibrio sp. strain G11 cultured with lactate, $\mathrm{H}_{2} / \mathrm{CO}_{2}$ overpressure, or hydrogen emanating from the coupon reduced sulfate at $1.08 \pm 0.006$, $0.36 \pm 0.06$, and $0.16 \pm 0.09 \mathrm{mM} \mathrm{SO}_{4} \bullet$ day $^{-1}$, respectively (Figure $\mathrm{S} 15)$. Thus, even though similar sulfate reduction rates were measured between cultures and co-cultures from experiment 1, the instantaneous corrosion rates as well as localized corrosion were substantially less within these repeat incubations (Table 4).

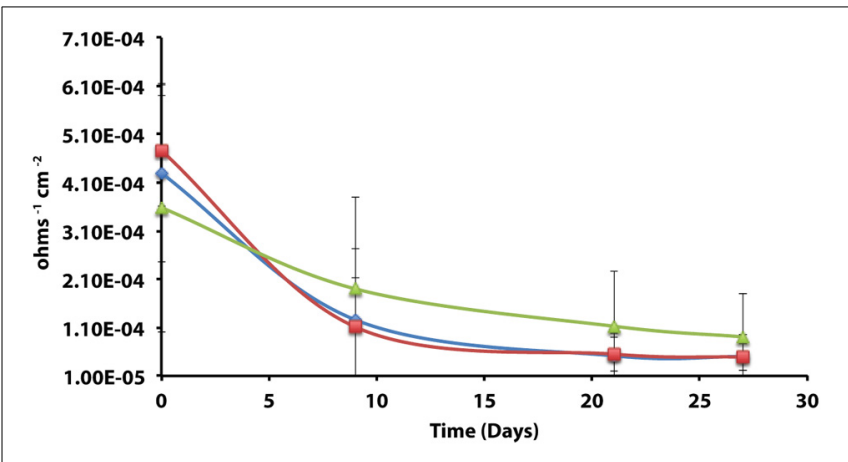

FIGURE 5 | Instantaneous corrosion rates $(1 / R p)$ for axenic incubations of Desulfovibrio sp. strain G11 cultured autotrophically on $138 \mathrm{kPa}$ of $\mathrm{H}_{2} / \mathrm{CO}_{2}(\mathrm{O})$ and hydrogen from the metal surface $(\square)$, as well as an uninoculated basal medium controls $(\triangle)$ amended with $138 \mathrm{kPa}$ of $\mathrm{H}_{2} / \mathrm{CO}_{2}$ or $\mathrm{N}_{2} / \mathrm{CO}_{2}$ (standard deviation incubations $n=3$, medium controls $n=2$ ).

\section{CORROSIVITY OF SPENT MEDIA}

The apparent corrosivity of uninoculated controls (Table 4) caused us to question the role of parent substrates and metabolic end products in exacerbating coupon damage. This prompted an experiment wherein acetate and sulfide were exogenously added to the sterile basal medium to simulate the concentration of these substances following the metabolism of crotonate by a co-culture of S. aciditrophicus strain SB and Desulfovibrio sp. strain G11. The same thing was done to simulate the products acetate and sulfide associated with lactate metabolism by Desulfovibrio sp. strain G11. These incubation conditions were chosen because localized corrosion was consistently associated with the production of acetate and sulfide. The results indicated that instantaneous corrosion rates typically ranged between $10^{-4}$ and $10^{-5} \mathrm{ohms}^{-1} \mathrm{~cm}^{-2}$, and pitting was not detected on any of the metal surfaces (Table 4; Figures S17-S20).

\section{STATISTICAL TESTS}

In order to determine whether statistical differences existed between the various experimental treatments, incubations were grouped according to end product production. These treatment groups included: sulfide only, sulfide and acetate, acetate only, methane, and uninoculated media controls. The treatment groups were then assessed by plotting the number of pits vs. the instantaneous corrosion rates for the individual microbial incubations (Figure 6A), and then compared to the uninoculated media controls (Figure 6B). The results suggested that when sulfide and acetate were produced as end products, corrosion was elevated relative to other microbial incubations as well as to the media controls (Figure 6). To further examine these differences, the surface damage for each coupon was compared using a Bayesian multilevel model. Figure 7 displays the 63 histograms of points collected from the profilometer (i.e., one histogram for each coupon) separated into the five treatment groups. A histogram that is concentrated near the top of a panel (e.g., $-5 \mu \mathrm{m}$ ) indicates less surface damage than a histogram concentrated closer to the bottom (e.g., $-20 \mu \mathrm{m}$ ). A value of $0 \mu \mathrm{m}$ represents the highest point on the coupon's surface. The histograms are 


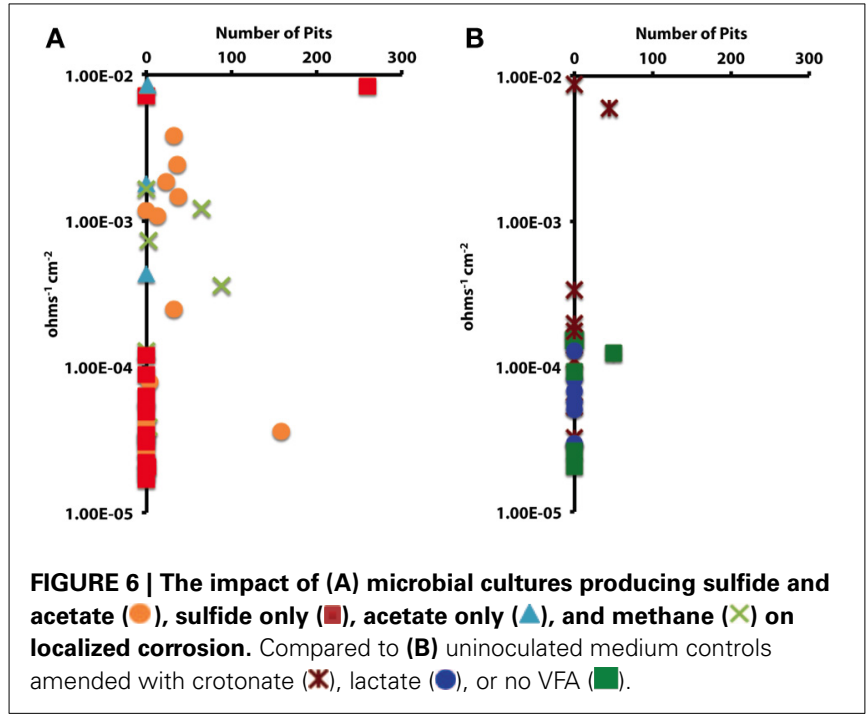

skewed down, indicating that the depth of the (numerous) points are greater than the height of the (infrequent) peaks. The results indicated that incubations producing both sulfide and acetate as end products was the only treatment group that corroded significantly more than the media controls $(p=0.016)$; typically the mean surface damage for these coupons was $2.2 \mu \mathrm{m}$ deeper than the uninoculated media controls.

\section{DISSCUSSION}

Anaerobic hydrocarbon degradation is an important ecological process within petroleum-laden environments, and one potential consequence of this metabolic activity is the sulfide-induced corrosion of carbon steel. However, the inherent complexity of the natural environment often makes it difficult to ascertain the biotic and abiotic factors that substantially influence biocorrosion. Our approach was to investigate this process in a more defined manner. That is, biocorrosion can be viewed as the interaction between electron donors of interest, a specific inoculum, the prevailing environmental conditions, and the composition of the metal (Suflita et al., 2013). Thus, we used defined microbial systems wherein the biological interactions with the electron donors were known and the metabolic end products could be reasonably anticipated. More specifically, we explored the impact of sulfate as an electron acceptor on metal biocorrosion in defined microbial assemblages and compared the damage to coupons when the same organisms were cultivated as syntrophic partnerships.

The corrosivity of the alkane-degrading, sulfate-reducing bacterium D. alkanexedens strain ALDC was previously assessed and was found to produce higher instantaneous corrosion rates and more pits compared to an uninoculated medium control containing $20 \mathrm{mM}$ sulfide (Suflita et al., 2013). Presumably, the production of sulfide by $D$. alkanexedens strain ALDC from $n$-decane oxidation was responsible for the increase in instantaneous corrosion rate and localized corrosion. In this study, when axenic incubations of $D$. alkanexedens strain ALDC were cultured on $n$-decane under sulfate-reducing conditions, instantaneous corrosion rates were $\sim 10$ times higher than comparable pure cultures

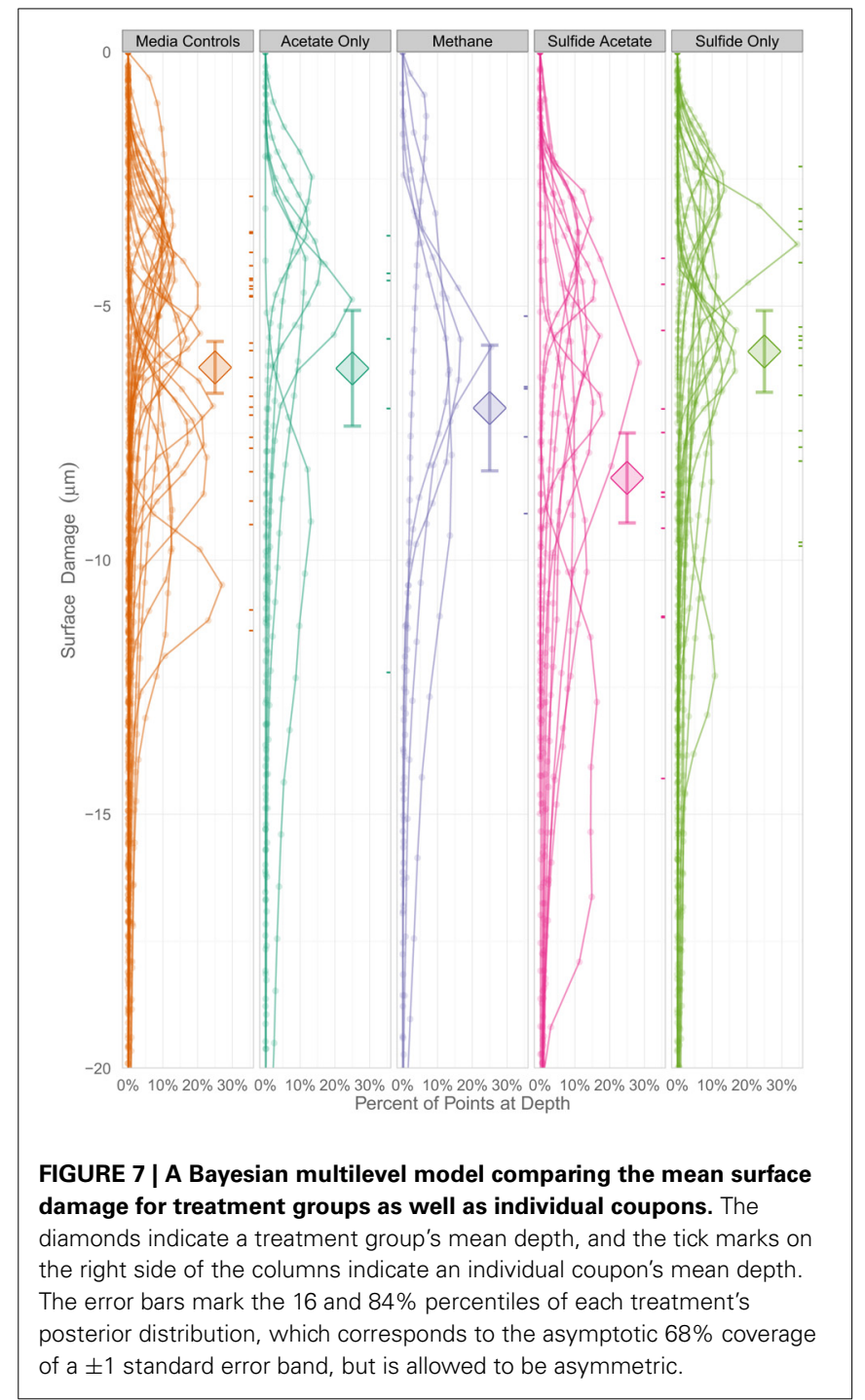

of $M$. hungatei strain JF-1 grown on $\mathrm{H}_{2} / \mathrm{CO}_{2}$ or in a co-culture of the two microorganisms (Figure 2). Pitting also decreased when coupons were incubated with $M$. hungatei strain JF-1 alone or with the co-culture (Table 4; Figure S8). The biological replicates of $D$. alkanexedens strain ALDC pure culture incubations had similar sulfate reduction and instantaneous corrosion rates (Figure 2; Figure S5); however, despite these similarities, the replicate incubations had a high variability in the number of pits observed on the individual coupons (Table 4). This result suggests that the coupons were differentially pitting even though the replicate incubations were biologically and chemically similar. Variability in localized corrosion was also observed in both the co-culture and the uninoculated control incubations, in which a single replicate produced pits under the respective incubation conditions (Table 4). This result suggested that pitting was not specifically a function of sulfide production, as this end product was not produced in either incubation. Nevertheless, coupon pitting under methanogenic conditions as well as with uninoculated controls was a relatively rare occurrence compared to incubations under sulfate-reducing conditions (Figures 6, 7; Figure S21). 
Previous research has suggested that the acetate concentration can exacerbate carbon steel corrosion by multiple mechanisms (Crolet et al., 1999; Hedges and McVeigh, 1999; Garsany et al., 2003; Suflita et al., 2008). At less than circumneutral pH values, at least some fraction of the acetate will exist as acetic acid and cause direct damage to metal surfaces. Therefore, it may be that $S$. aciditrophicus strain SB can contribute to corrosion through the production of acetate from the metabolism of fatty acids as a pure culture or when in syntrophic partnership. However, the instantaneous corrosion rates were not significantly different between axenic cultures of $S$. aciditrophicus strain SB and co-culture incubations with $M$. hungatei strain JF-1 or Desulfovibrio sp. strain G11 (Figure 3). However, when the coupons were subject to profilometric analysis, pitting was largely restricted to co-culture incubations of S. aciditrophicus strain SB and Desulfovibrio sp. strain G11 (Table 4 experiment 1; Figure S12). When S. aciditrophicus strain SB and Desulfovibrio sp. strain G11 co-culture incubations were repeated, instantaneous corrosion rates were substantially slower (Table 4 experiment 2; Figure S13), but pits were identified on all metal samples from the incubations (Table 4 experiment 2; Figure S14). Despite the $18 \mathrm{mM}$ difference in crotonate metabolism between the experiments (Figures S11, S15), the $S$. aciditrophicus strain SB and Desulfovibrio sp. strain G11 coculture was the only incubation condition that produced localized corrosion in all six replicates. The results suggest that corrosion is likely increased due to the production of both acetate and sulfide during the metabolism of crotonate under sulfate-reducing conditions.

The impact of lactate-grown Desulfovibrio sp. strain G11 on metal corrosion was similarly evaluated. This organism incompletely oxidizes lactate to acetate and uses sulfate as an external electron acceptor. Thus, if localized corrosion is at least a function of both acetate and sulfide production, pitting would be expected on the metal coupons. In fact, the results are largely consistent with this contention in that pitting occurred on metal surfaces in two of three replicate incubations (Table 4 experiment 1; Figure S12). Nevertheless, when these incubations were repeated, the instantaneous corrosion rates were substantially lower and no pits were evident by profilometry (Table 4 experiment 2; Figure S14) even though similar rates of sulfate reduction were measured between the two experiments (Figures S10, S16). The variability in pitting behavior between replicate incubations and repeat experiments that exhibited similar rates of substrate utilization and metabolic end product formation is enigmatic. Since the biological activity and the resulting chemistry is both defined and controlled, we are forced to attribute the variability to incubation components we could not adjust. More specifically, we presume the variations can somehow be attributed to differences in the composition of the carbon steel coupons. However, according to the bulk analysis by the manufacturer, the coupons were compositionally similar (Table S1).

To exemplify, autotrophically cultured Desulfovibrio sp. strain G11 cultures are able to reduce sulfate at different rates depending on whether the coupon itself served as a hydrogen source or if the electron donor was supplied exogenously. In the latter case, the sulfate reduction rate was comparable to the co-culture of this organism with S. aciditrophicus strain SB (Figures S10,
S16). However, corrosion measures were substantially less with the pure culture relative to the co-culture, thus implicating acetate as a confounding factor in sulfide-induced corrosion. (Table 4 experiments 1 and 2). The only exception is one replicate from experiment two (Table 4), which produced an instantaneous corrosion rate of $10^{-3} \mathrm{ohms}^{-1} \mathrm{~cm}^{-2}$ and had pitting on the side of the coupon (data not shown). Thus, only one metal coupon out of twelve substantially corroded upon exposure to autotrophicallygrown Desulfovibrio sp. strain G11. Considering the relatively small amount of sulfide produced in these incubations $(\sim 2 \mathrm{mM})$, the lack of acetate production, and the relatively consistent levels of coupon corrosion, differences in the corrosion behavior of a single replicate also point to potential differences in the coupons themselves.

Methanogens such as Methanobacterium thermoautotrophicum (Lorowitz et al., 1992) and Methanococcus maripaludis strain KA1 (Uchiyama et al., 2010) have been previously described to stimulate corrosion by either scavenging hydrogen or direct electron utilization from the surface of the metal coupons, respectively. $M$. hungatei strain JF-1 has not been reported to utilize either of these corrosion mechanisms, and when the metal was the only source of hydrogen in the incubation, methane production, instantaneous corrosion rates, and pitting were all negligible (data not shown) over the incubation period. Additionally, incubations of $M$. hungatei strain JF-1 amended with $138 \mathrm{kPa}$ of $\mathrm{H}_{2} / \mathrm{CO}_{2}$ did not exacerbate corrosion on any metal sample (Table 4). However, M. hungatei strain JF-1 was associated with corrosion within two incubations. The first was in co-culture with $D$. alkanexedens strain ALDC (Table 4, replicate 1, 64 pits; Figure S8), and the second was in co-culture with S. aciditrophicus strain SB (Table 4 experiment 1, replicate 1, 88 pits; Figure $\mathrm{S} 12)$. Considering methane production was similar between replicate incubations (Figures S6, S9), the lack of sulfide production, and that pits were not detected on any other metal samples, the corrosion of these particular coupons are also attributed to the variability in the elemental composition of the metal sample.

Uninoculated media controls containing crotonate and lactate occasionally produced higher instantaneous corrosion rates (Figures 2, 3) than the corresponding inoculated incubations, and one replicate of a crotonate exposed coupon was found to have 45 pits at the end of the incubation (Table 4 experiment 1; Figure S12). Thus, we concluded that the potential for metal corrosion due to exposure to various fatty acids could be important considering that formate, acetate, propionate, butyrate, and benzoate have all been detected in oil reservoirs with concentrations exceeding $20 \mathrm{mM}$ (Magot et al., 2000). However, when comparable uninoculated controls were specifically evaluated, corrosion was found to be negligible (Table 4 experiment 2). Additionally, corrosion was not stimulated on metal samples that were exposed to uninoculated incubations amended with crotonate, lactate, acetate and sulfide to represent the spent medium of $S$. aciditrophicus strain SB and Desulfovibrio sp. strain G11 co-cultures as well as lactate-amended Desulfovibrio sp. strain G11 pure cultures (Table 4; Figures S17-S20). Thus, the differences between our initial observations and subsequent experimentation (Table 4) also seem to be a function of the variable nature of the coupons, despite identical manufacturer bulk analyses. 
Biocorrosion experiments exhibited high standard deviations for instantaneous corrosion rates and pitting for metal samples that was independent of inoculum type, biomass levels, initial substrate concentration, rates of microbial activity, or the degree of end product formation. Eliminating these factors as major contributors to the measured variability, forces us to attribute the large standard deviations to inconsistencies in the individual metal coupon samples. The bulk analysis of the metal from the manufacturer does not lend credence to this suggestion. However, low grade carbon steel is known to contain manganese sulfide inclusions $(\mathrm{MnS})$ that are sites for pitting initiation and pit propagation (Vuillemin et al., 2003; Avci et al., 2013). The density of these submicron sized inclusions on carbon steel is typically thousands per square millimeter (Avci et al., 2013). It is unknown if the inclusions are evenly (randomly) distributed in metal or if they are clustered (heterogeneous) to any degree. It also seems clear that some inclusions are more susceptible as sites of pit initiation than others (Wranglen, 1974; Davis, 2013). Thus, both the distribution and the reactivity of inclusion bodies within a metal sample could substantially influence corrosion processes and help explain why seemingly similar metal samples may behave differently in corrosion experiments.

There was generally no agreement between instantaneous corrosion rates and the number of pits; that is localized corrosion did not always occur on coupons with higher $\left(10^{-3} \mathrm{ohms}^{-1}\right.$ $\mathrm{cm}^{-2}$ ) $1 / R_{p}$ values (Table 4; Figure 6). Electrochemical measurements, such as LPR, are considered highly sensitive and accurate ( $<0.5 \%$ error; Jones, 1996) for monitoring generalized corrosion, and profilometry can detect and quantify pits on a micron-scale. However, considering these methods were not always in agreement, other corrosion analyses would seem pertinent (e.g., weight loss, total iron determinations, manganese loss). Additionally, by differentially focusing our analysis on bulk fluids, the findings may not reflect reactions occurring in a biofilm on the metal surface. Localized metabolic activities in microbial biofilms, particularly the production of organic acids, can cause the $\mathrm{pH}$ to substantially decrease at the metal surface (Vroom et al., 1999). These points notwithstanding, our results generally show that localized corrosion was elevated when coupons were exposed to sulfide-producing cultures relative to methanogenic cultures or to uninoculated controls (Figures 6, 7; Figure S21).

The major implications of this work are that the anaerobic biodegradation of hydrocarbons or associated fatty acid intermediates linked to sulfate reduction can have important consequences with respect to the biocorrosion of carbon steel. That is, when sulfate is available as an electron acceptor, microbial assemblages will produce sulfide and low molecular weight organic acids that generally increase the corrosion of carbon steel. However, when the same organisms are in sulfate-limited environments and forced to live a syntrophic existence with a methanogen, biocorrosion is substantially reduced. These trends must be considered fairly general with more specific inferences being somewhat masked by the surprisingly high degree of variability associated with the corrosion assessments. Since the biological and chemical characteristics of the incubations were controlled, we were forced to attribute the high variability to differences with the metal samples themselves.

\section{AUTHOR CONTRIBUTIONS}

All authors contributed equally to this work. Christopher N. Lyles was responsible for designing electrochemical and profilometry analyses to assess the corrosion of metal coupons, as well as data analysis, interpretation of results, and drafting the manuscript. Huynh M. Le cultured the microorganisms and also contributed to data analysis and interpretation. William Howard Beasley provided the statistical analyses. Michael J. McInerney critically revised the manuscript as well as provided much needed insight into a variety of aspects surrounding syntrophic microorganisms. Joseph M. Suflita is the corresponding author and has overseen all aspects of this project for both scientific accuracy and integrity.

\section{ACKNOWLEDGMENTS}

This work was supported by a grant (Award No. N0001408WX20857) from the Office of Naval Research. We would also like to thank Karen Cloke of Phillips 66 for her assistance with the profilometry analysis.

\section{SUPPLEMENTARY MATERIAL}

The Supplementary Material for this article can be found online at: http://www.frontiersin.org/journal/10.3389/fmicb.2014. 00114/abstract

\section{REFERENCES}

Aktas, D. F., Lee, J. S., Little, B. J., Ray, R. I., Davidova, I. A., Lyles, C. N., et al. (2010). Anaerobic metabolism of biodiesel and its impact on metal corrosion. Energy Fuels 24, 2924-2928. doi: 10.1021/ef100084j

Anderson, I., Ulrich, L. E., Lupa, B., Susanti, D., Porat, I., Hooper, S. D., et al. (2009). Genomic characterization of methanomicrobiales reveals three classes of methanogens. PLoS ONE 4:e5797. doi: 10.1371/journal.pone.0005797

ASTM Standard A576-90b. (2006) (reapproved 2012). "Standard practice for preparing, cleaning, and evaluating corrosion test specimens," in Corrosion of Metals; Wear and Erosion (West Conshohocken, PA: ASTM International).

Avci, R., Davis, B. H., Wolfenden, M. L., Beech, I. B., Lucas, K., and Paul, D. (2013). Mechanism of MnS-mediated pit initiation and propagation in carbon steel in an anaerobic sulfidogenic media. Corros. Sci. 76, 267-274. doi: 10.1016/j.corsci.2013.06.049

Bader, M. S. H. (2007). Sulfate removal technologies for oil fields seawater injection operations. J. Pet. Sci. Eng. 55, 93-110. doi: 10.1016/j.petrol.2006.04.010

Bates, D. M. (2010). Ime4: Mixed-Effects Modeling with R. Available online at: http://lme4.r-forge.r-project.org/lMMwR/lrgprt.pdf

Blake, D., and Rowland, F. (1988). Continuing worldwide increase in tropospheric methane, 1978 to 1987. Science 239, 1129-1131. doi: 10.1126/science.239.4844.1129

Callaghan, A. V. (2013). Enzymes involved in the anaerobic oxidation of nalkanes: from methane to long-chain paraffins. Front. Microbiol. 4:89. doi: 10.3389/fmicb.2013.00089

Cozzarelli, I. M., Baedecker, M. J., Eganhouse, R. P., and Goerlitz, D. F. (1994). The geochemical evolution of low-molecular-weight organic acids derived from the degradation of petroleum contaminants in groundwater. Geochim. Cosmochim. Acta 58, 863-877. doi: 10.1016/0016-7037(94)90511-8

Crolet, J. L., Dugstad, A. L., and Thevenot, N. L. (1999). Role of free acetic acid on the $\mathrm{CO}_{2}$ corrosion of steels. Corrosion 1-16.

Davidova, I. A., Duncan, K. E., Choi, O. K., and Suflita, J. M. (2006). Desulfoglaeba alkanexedens gen. nov., sp. nov., an n-alkane-degrading, sulfate-reducing bacterium. Int. J. Syst. Evol. Microbiol. 56, 2737-2742. doi: 10.1099/ijs.0. 64398-0

Davis, B. H. (2013). Anaerobic Pitting Corrosion of Carbon Steel in Marine Sulfidogenic Environment. M.Sc. thesis, Physics Department, Montana State University, 156.

Dinh, H. T., Kuever, J., Mußmann, M., Hassel, A. W., Stratmann, M., and Widdel, F. (2004). Iron corrosion by novel anaerobic microorganisms. Nature 427, 829-832. doi: 10.1038 /nature 02321 
Dolfing, J., Larter, S. R., and Head, I. M. (2008). Thermodynamic constraints on methanogenic crude oil biodegradation. ISME J. 2, 442-452. doi: 10.1038/ismej.2007.111

Enning, D., and Garrelfs, J. (2014). Corrosion of iron by sulfate-reducing bacteria: new views of an old problem. Appl. Environ. Microbiol. 80, 1226-1236. doi: 10.1128/AEM.02848-13

Enning, D., Venzlaff, H., Garrelfs, J., Dinh, H. T., Meyer, V., Mayrhofer, K., et al. (2012). Marine sulfate-reducing bacteria cause serious corrosion of iron under electroconductive biogenic mineral crust. Environ. Microbiol. 14, 1772-1787. doi: 10.1111/j.1462-2920.2012.02778.x

Ferry, J. G., Smith, P. H., and Wolfe, R. S. (1974). Methanospirillum, a new genus of methanogenic bacteria, and characterization of Methanospirillum hungatii sp. nov. Int. J. Syst. Bacteriol. 24, 465-469. doi: 10.1099/00207713-24-4-465

Garsany, Y., Pletcher, D., and Hedges, B. (2003). "The role of acetate in $\mathrm{CO}_{2}$ corrosion of carbon steel: studies related to oilfeild conditions," in Corrosion 1-15. NACE International, Paper no. 03324 (Houston, TX).

Gieg, L. M., Duncan, K. E., and Suflita, J. M. (2008). Bioenergy production via microbial conversion of residual oil to natural gas. Appl. Environ. Microbiol. 74 3022-3029. doi: 10.1128/AEM.00119-08

Hadfield, J. D. (2010). MCMC methods for multi-response generalized linear mixed models: the MCMCglmm R package. J. Stat. Softw. 33, 1-22.

Hamilton, W. A. (1985). Sulphate-reducing bacteria and anaerobic corrosion. Annu. Rev. Microbiol. 39, 195-217. doi: 10.1146/annurev.mi.39.100185. 001211

Head, I. M., Aitken, C. M., and Group, P. R. (2010). "Hydrocarbon degradation in petroleum reservoirs," in Handbook of Hydrocarbon and Lipid Microbiology, ed K. N. Timmis (Berlin; Heidelberg: Springer Berlin Heidelberg), 3098-3107.

Hedges, B., and McVeigh, L. (1999). "The role of acetate in $\mathrm{CO}_{2}$ corrosion: the double whammy," in Corrosion 1-18. NACE International, Paper no. 21 (Houston, TX)

Heider, J., and Schühle, K. (2013). "Anaerobic biodegradation of hydrocarbons including methane," in The Prokaryotes, eds E. Rosenberg, E. F. DeLong, S. Lory, E. Stackebrandt, and F. Thompson (Berlin; Heidelberg: Springer Berlin Heidelberg), 605-634

Hopkins, B. T., McInerney, M. J., and Warikoo, V. (1995). Evidence for anaerobic syntrophic benzoate degradation threshold and isolation of the syntrophic benzoate degrader. Appl. Environ. Microbiol. 61, 526-530.

Hubert, C., and Voordouw, G. (2007). Oil field souring control by nitratereducing Sulfurospirillum spp. that outcompete sulfate-reducing bacteria for organic electron donors. Appl. Environ. Microbiol. 73, 2644-2652. doi: 10.1128/AEM.02332-06

Jackson, B., Bhupathiraju, V., Tanner, R., Woese, C., and McInerney, M. (1999). Syntrophus aciditrophicus sp. nov., a new anaerobic bacterium that degrades fatty acids and benzoate in syntrophic association with hydrogenusing microorganisms. Arch. Microbiol. 171, 107-114. doi: 10.1007/s002030 050685

Jenneman, G. E., McInerney, M. J., and Knapp, R. M. (1986). Effect of nitrate on biogenic sulfide production. Appl. Environ. Microbiol. 51, 1205-1211.

Jones, D. A. (1996). "Chapter 3: Electrochemical kinetics of corrosion," in Principles and Preventions of Corrosion 2nd edn, eds B. Stenquist, R. Kernan, and P. Daly (Upper Saddle River, NJ: Prentice Hall), 75-115.

Jones, D. M., Head, I. M., Gray, N. D., Adams, J. J., Rowan, A. K., Aitken, C. M., et al. (2008). Crude-oil biodegradation via methanogenesis in subsurface petroleum reservoirs. Nature 451, 176-180. doi: 10.1038/nature06484

Kermani, M. B., and Morshed, A. (2003). Carbon dioxide corrosion in oil and gas production-a compendium. Corrosion 59, 659-683. doi: 10.5006/1.3277596

King, R. A., and Miller, J. D. A. (1971). Corrosion by sulphate-reducing bacteria. Nature 233, 491-492. doi: 10.1038/233491a0

King, R. A., Miller, J. D. A., and Smith, J. S. (1973a). Corrosion of mild steel by iron sulphides. Br. Corros. J. 8, 137-141. doi: 10.1179/000705973798322251

King, R. A., Miller, J. D. A., and Wakerley, D. S. (1973b). Corrosion of mild steel in cultures of sulphate-reducing bacteria-effect of changing the soluble iron concentration during growth. Br. Corros. J. 8, 89-93. doi: 10.1179/bcj.1973. 8.2.89

King, R. A., and Wakerley, D. S. (1972). Corrosion of mild steel by ferrous sulphide Br. Corros. J. 8, 41-45. doi: 10.1179/000705973798322521

Lorowitz, W. H., Nagle, D. P., and Tanner, R. S. (1992). Anaerobic oxidation of elemental metals coupled to methanogenesis by Methanobacterium thermoautotrophicum. Environ. Sci. Technol. 26, 1606-1610. doi: 10.1021/es00032a018
Lyles, C. N., Aktas, D. F., Duncan, K. E., Callaghan, A. V., Stevenson, B. S., and Suflita, J. M. (2013). Impact of organosulfur content on diesel fuel stability and implications for carbon steel corrosion. Environ. Sci. Technol. 47, 6052-6062. doi: 10.1021/es4006702

Magot, M., Ollivier, B., and Patel, B. K. (2000). Microbiology of petroleum reservoirs. Antonie Van Leeuwenhoek 77, 103-116. doi: 10.1023/A:100243 4330514

Mayumi, D., Dolfing, J., Sakata, S., Maeda, H., Miyagawa, Y., Ikarashi, M., et al. (2013). Carbon dioxide concentration dictates alternative methanogenic pathways in oil reservoirs. Nat. Commun. 4, 1-6. doi: 10.1038/ ncomms 2998

McInerney, M., Bryant, M., and Pfennig, N. (1979). Anaerobic bacterium that degrades fatty acids in syntrophic association with methanogens. Arch. Microbiol. 122, 129-135. doi: 10.1007/BF00411351

McInerney, M. J., Rohlin, L., Mouttaki, H., Kim, U., Krupp, R. S., Rios-Hernandez, L., et al. (2007). The genome of Syntrophus aciditrophicus: life at the thermodynamic limit of microbial growth. Proc. Natl. Acad. Sci. U.S.A. 104, 7600-7605. doi: 10.1073/pnas.0610456104

McInerney, M. J., Wofford, N. Q., and Sublette, K. L. (1996). Microbial control of hydrogen sulfide production in a porous medium. Appl. Biochem. Biotechnol. 57-58, 933-944. doi: 10.1007/BF02941774

Mouttaki, H., Nanny, M. A., and McInerney, M. J. (2007). Cyclohexane carboxylate and benzoate formation from crotonate in Syntrophus aciditrophicus. Appl. Environ. Microbiol. 73, 930-938. doi: 10.1128/AEM. 02227-06

Nemati, M., Jenneman, G. E., and Voordouw, G. (2001). Impact of nitrate-mediated microbial control of souring in oil reservoirs on the extent of corrosion. Biotechnol. Prog. 17, 852-859. doi: 10.1021/bp01 $0084 \mathrm{v}$

Reiffenstein, R. J., Hulbert, W. C., and Roth, S. H. (1992). Toxicology of hydrogen sulfide. Annu. Rev. Pharmacol. Toxicol. 32, 109-134. doi: 10.1146/annurev.pa.32.040192.000545

Struchtemeyer, C. G., Duncan, K. E., and McInerney, M. J. (2011). Evidence for syntrophic butyrate metabolism under sulfate-reducing conditions in a hydrocarbon-contaminated aquifer. FEMS Microbiol. Ecol. 76, 289-300. doi: 10.1111/j.1574-6941.2011.01046.x

Suflita, J. M., Lyles, C. N., Aktas, D. F., and Sunner, J. (2013). "Chapter 16: Biocorrosion issues associated with ultra low sulfur diesel and biofuel blends," in Understanding Biocorrosion: Fundamentals and Applications (Woodhead Publishing), (in press).

Suflita, J. M., Phelps, T. J., and Little, B. (2008). Carbon dioxide corrosion and acetate: a hypothesis on the influence of microorganisms. Corrosion 64, 854-859. doi: 10.5006/1.3279919

Tanner, R. S. (2002). "Cultivation of bacteria and fungi," in Manual of Environmental Microbiology, eds R. L. Crawford, G. R. Knudsen, M. J. McInerney, and L. D. Stetzenback (Washington, DC: ASM Press), 62-70.

Teske, A. (2010). "Sulfate-reducing and methanogenic hydrocarbon-oxidizing microbial communities in the marine environment," in Handbook of Hydrocarbon and Lipid Microbiology, ed K. N. Timmis (Berlin; Heidelberg: Springer Berlin Heidelberg), 2204-2216.

Uchiyama, T., Ito, K., Mori, K., Tsurumaru, H., and Harayama, S. (2010). Ironcorroding methanogen isolated from a crude-oil storage tank. Appl. Environ. Microbiol. 76, 1783-1788. doi: 10.1128/AEM.00668-09

Van Stempvoort, D. R., Armstrong, J., and Mayer, B. (2007). Seasonal recharge and replenishment of sulfate associated with biodegradation of a hydrocarbon plume. Ground Water Monit. R. 27, 110-121. doi: 10.1111/j.17456592.2007.00168.x

Van Stempvoort, D. R., Millar, K., and Lawrence, J. R. (2009). Accumulation of short-chain fatty acids in an aquitard linked to anaerobic biodegradation of petroleum hydrocarbons. Appl. Geochem. 24, 77-85. doi: 10.1016/j.apgeochem.2008.11.004

Vroom, J. M., De Grauw, K. J., Gerritsen, H. C., Bradshaw, D. J., Marsh, P. D., Watson, G. K., et al. (1999). Depth penetration and detection of $\mathrm{pH}$ gradients in biofilms by two-photon excitation microscopy. Appl. Environ. Microbiol. 65, 3502-3511.

Vuillemin, B., Philippe, X., Oltra, R., Vignal, V., Coudreuse, L., Dufour, L. C., et al. (2003). SVET, AFM and AES study of pitting corrosion initiated on MnS inclusions by microinjection. Corros. Sci. 45, 1143-1159. doi: 10.1016/S0010938X(02)00222-6 
Warikoo, V., McInerney, M. J., Robinson, J. A., and Suflita, J. M. (1996). Interspecies acetate transfer influences the extent of anaerobic benzoate degradation by syntrophic consortia. Appl. Environ. Microbiol. 62, 26-32.

Wranglen, G. (1974). Pitting and sulphide inclusions in steel. Corros. Sci. 14, 331-349. doi: 10.1016/S0010-938X(74)80047-8

Conflict of Interest Statement: The authors declare that the research was conducted in the absence of any commercial or financial relationships that could be construed as a potential conflict of interest.

Received: 09 November 2013; paper pending published: 13 January 2014; accepted: 07 March 2014; published online: 01 April 2014.
Citation: Lyles CN, Le HM, Beasley WH, McInerney MJ and Suflita JM (2014) Anaerobic hydrocarbon and fatty acid metabolism by syntrophic bacteria and their impact on carbon steel corrosion. Front. Microbiol. 5:114. doi: 10.3389/fmicb. 2014.00114

This article was submitted to Aquatic Microbiology, a section of the journal Frontiers in Microbiology.

Copyright (c) 2014 Lyles, Le, Beasley, McInerney and Suflita. This is an open-access article distributed under the terms of the Creative Commons Attribution License (CC BY). The use, distribution or reproduction in other forums is permitted, provided the original author(s) or licensor are credited and that the original publication in this journal is cited, in accordance with accepted academic practice. No use, distribution or reproduction is permitted which does not comply with these terms. 